\title{
Measuring teaching quality: some key issues
}

\section{Guri Skedsmo ${ }^{1,2} \cdot$ Stephan Gerhard Huber ${ }^{3}$}

Published online: 7 June 2019

(C) Springer Nature B.V. 2019

In recent decades, numbers have become fundamental to education governance. Examination and tests results are used to categorise, compare, rank and position individuals, organisations, regions and countries. Although relatively new in education contexts, this form of governance has a long history in other areas where states employ systematic collection of demographic and economic data to monitor their populations (Ball 2015). Most often related to student performance, data have gained in importance as a means of summarising complex phenomena and dimensions across different locations and over time to identify and compare effective educational practices (cf. Hacking 1983) in ways that indicate 'neutrality' and 'objectivity' (Petterson et al. 2017). Embedded in performance management, these data are used to hold individuals, organisations and systems to account and as a basis for improvement (Verger et al. 2019; Prøitz et al. 2017). For example, the extensive research on measures to inform and improve teaching quality, actions and conditions that affect student outcomes as well as studies of teacher professionalisation. The articles in this issue address a number of topics related to the use of performance data, with particular reference to teaching quality.

\section{Articles in this issue of EAEA, 2/2019}

In the first article, Torres, Palhares and Afonso investigate the expansion of a meritocratic culture in the Portuguese secondary education system and the development of governing and management strategies based on student performance data, with

Guri Skedsmo

guri.skedsmo@phsz.ch

$\square$ Stephan Gerhard Huber

stephan.huber@phzg.ch

1 Institute for Research on Professions and Professional Learning, Schwyz University of Teacher Education, Goldau, Switzerland

2 Department of Teacher Education and School Research, University of Oslo, Oslo, Norway

3 Institute for the Management and Economics of Education, University of Teacher Education Zug, Zug, Switzerland 
particular emphasis on the best students. According to the authors, academic performance and ranking position express 'school excellence' and are used as a marketing strategy to attract the best students. As characterised here, this increasing neomeritocratic selectivity seems to develop without visible resistance and stands in contrast to the previous investment in equitable basic education for all.

Using Swedish PIRLS data from 2011, Johansson and Myrberg investigate the relationship between fourth grade reading achievement, teacher specialisation and student perceptions of instructional quality. In comparing two measures of teacher quality, they report a positive relationship between student reading achievement and teacher specialisation for the specific grade and subject but find no association between perceived instructional quality and reading achievement or between instructional quality and teacher specialisation. These findings align with existing research linking teacher specialisation, effective teaching practices and student achievement. On that basis, the authors question the validity of student evaluations of teacher classroom practices, and they argue for the potential value of a model of teacher specialisation to improve teaching quality and student achievement.

Measures of teaching quality are again a key topic for Fischer, Praetorius and Klieme. In cross-country comparisons of large-scale data commonly used to benchmark system effectiveness as a basis for education policy, it is assumed that measuring instruments work in much the same way everywhere. To investigate data comparability across 15 countries, the authors analyse PISA 2012 data in relation to three dimensions of teaching quality: student support, classroom management and cognitive activation. Their main finding is that the comparability of teaching quality measures is limited across linguistically diverse countries, and that such comparisons must take account of both linguistic and cultural differences. Based on their analysis, the authors suggest new and flexible approaches to assess data comparability.

The fourth article explores the effectiveness of teacher education. Based on data from a longitudinal study of 1451 student teachers from 18 universities and teacher training colleges in Germany and Austria, Klemenz, König and Schaper investigate the relationship between learning opportunities in teacher education and general pedagogical proficiency - in other words, the knowledge acquired during teacher education and how this is affected by opportunities to learn. They report that instructional quality in pedagogy seminars and lectures is linked to pedagogical proficiency as represented by theoretical knowledge. Higher proficiency levels are characterised by complex cognitive processes that also require practical knowledge acquired through classroom experience. The authors discuss important implications of these findings for teacher education.

\section{Some reflections}

The first article shows how the use of performance data as part of a marketing strategy to attract the best students installs competition, visibility and marketisation as key components of school governance (cf. Skedsmo 2018). In an article from 2006, Webb described similar phenomena in the American context as 'window dressing', in which selected aspects of school quality or even choreographed performances are seen to align with demands for accountability. 
Fischer, Praetorius and Klieme emphasise the problem of comparability in largescale international achievement tests and the need to consider cultural and linguistic differences. One implication of their findings is that to address 'the challenge of data and comparability' of PISA, it is insufficient to 'set quantifiable targets, indicators and benchmarks as a means of comparing best practice and as instruments for monitoring and reviewing the progress achieved in order to provide a basis for educational policy making' as suggested in the European Report on the Quality of School Education (European Commission 2000, p. 16). The findings presented in this article represent an important contribution to further use of data from large-scale achievement tests for researchers and policy makers.

Klemenz, König and Schaper's findings regarding the relationship between knowledge gained during teacher education, opportunities to learn and pedagogical proficiency highlight the need for teacher professionalisation to combine knowledge and experience from practical teaching situations with other forms of knowledge. Johansson and Myrberg's discussion of the consequences of increased quality control and auditing, which do not necessarily achieve the intended improvements in student learning, raises questions about whether occupational professionalism can be contested, possibly leading to the de-professionalisation of teachers. Both articles argue for perspectives on professionalisation which are in contrast to government professionalisation agendas for teaching and teacher education in many countries which create work conditions in schools in danger of diminishing or even undermining professionalism.

\section{References}

Ball, S. (2015). Education, governance and the tyranny of numbers. Journal of Education Policy, 30(3), 299301.

European Commission. (2000). The European Report on Quality of School Education.

Hacking, I. (1983). Representing and intervening: Introductory topics in the philosophy of natural science. Cambridge: Cambridge University Press.

Petterson, D., Popkewitz, T., \& Lindblad, S. (2017). In the grey zone: large scale assessment-based activities betwixt and between policy, research and practice. Nordic Journal of Studies in Educational Policy, 3(1), 29-41. https://doi.org/10.1080/20020317.2017.1316181.

Prøitz, T. S., Mausethagen, S., \& Skedsmo, G. (2017). Investigative modes in research on data use in education. Nordic Journal of Studies in Educational Policy, 3(1), 42-55. https://doi.org/10.1080 /20020317.2017.1326280.

Skedsmo, G. (2018). Comparison and benchmarking as governing processes in Norwegian schools. I. In L. M. Carvalho, L. Levasseur, M. Liu, R. Normand, \& D. A. Oliveira (Eds.), Education Policies and the Restructuring of the Educational Profession (pp. 137-158). Singapore: Springer.

Verger, A., Fontdevila, C., \& Parcerisa, L. (2019). Reforming governance through policy instruments: How and to what extent standards, tests and accountability in education spread worldwide. Discourse: Studies in the Cultural Politics of Education. https://doi.org/10.1080/01596306.2019.1569882.

Webb, T. (2006). The choreography of accountability. Journal of Education Policy, 21(2), 201-214. https://doi.org/10.1080/02680930500500450.

Publisher's note Springer Nature remains neutral with regard to jurisdictional claims in published maps and institutional affiliations. 